\title{
Clinical and immunological study of specific Mycobacterium bovis-BCG transfer factor in lambs
}

\author{
E.A. Nayyef ${ }^{1} \odot$, M.A. Al-Graibawi ${ }^{2} \odot$ \\ ${ }^{1}$ Department of Internal and Preventive Medicine, College of Veterinary Medicine, University of Fallujah, Al-Anbar, \\ ${ }^{2}$ Department of Internal and Preventive Medicine, College of Veterinary Medicine, University of Baghdad, Baghdad, Iraq
}

\section{Article information}

Article history:

Received August 29, 2021

Accepted October 29, 2021

Available online December 14, 2021

\section{Keywords:}

Transfer factor

Immunotherapy

IL-17

IFN- $\gamma$

MIF Cytokine

\section{Correspondence:}

E.A. Nayyef

aaylaf10@gmail.com

\begin{abstract}
This study was designed to prepare and evaluate the specific Mycobacterium bovis (M. bovis) Bacillus Calmette-Guerin (BCG) transfer factor (TF) from spleen cells of two lambs vaccinated subcutaneously $\mathrm{S} / \mathrm{C}$ with $\mathrm{BCG}$ vaccine twice 2 weeks' intervals, similarly one lamb injected with normal saline used as a donor of non-specific TF. The lambs were clinically examined at zero time and along 3 days post each immunization, then, delayed type hypersensitivity (DTH) was checked post 4 weeks. TF was obtained from spleen cells of the lambs, inspected for sterility; safety.TF was evaluated in 4 groups (five in each) of lambs 3-4 months old. The first group (recipient) was injected S/C with 2 $\mathrm{ml}$ of specific BCG-TF, similarly the 2nd, 3rd and 4th groups were injected with nonspecific TF, BCG and normal saline respectively. The clinical signs and DTH test were checked as described above, only the specific TF recipient and BCG vaccinated lambs gave a positive DTH test. The serum concentration of inerlukin-17 (IL-17), interferongamma (IFN- $\gamma)$ and migration inhibitory factor (MIF) cytokines were measured by Enzyme-linked immunosorbent assay (ELISA), which revealed a highly significant increase in the TF recipient lambs in comparison with the control and vaccinated groups. It concluded that the prepared specific $M$. bovis-BCG transfer factor was effective to induce cell mediated immunity via DTH and increasing the serum concentration of cytokines in recipient lambs.
\end{abstract}

DOI: 10.33899/ijvs.2021.131305.1939, (CAuthors, 2021, College of Veterinary Medicine, University of Mosul

This is an open access article under the CC BY 4.0 license (http://creativecommons.org/licenses/by/4.0/).

\section{Introduction}

Transfer factor, also called dialyzable leukocyte extract (DLE) or 'Lawrence transfer factor, firstly described in 1949 by Lawrence (1), it is very small molecular weight (lower than 5,000 Daltons), that able to transfer cellular immune responses from a sensitized host (donor) to nonsensitized one (recipient), and protect them against pathogens, its immunological activity was evaluated against many bacterial, viral, parasitic and fungal diseases (2). The general term transfer factor denotes numerous highly active biological agents that have a general immune correctors properties (immunomodulatory, immunizing and immunosubstituting), and are obtained from various biological sources such as, blood leucocytes, spleen, lymph node, yolks of bird eggs, colostrum of mammals $(3,4)$.

Since cellular immunity is essential for controlling of infectious disease, autoimmune disorders, cancer, immunodeficiency and allergies, TF is an immune regulator which activates cellular immunity, stimulates cytokine synthesis and regulates immune function and can be applied for the treatment and prevention of these cases (5). Its essential mechanism of action has been proposed at the level of cellular immune responses as it induces synthesis of IL 1, IL17, MIF and IFN- $\gamma$ cytokines (6). Cytokines are a low molecular weight regulatory peptide that participates in both types of immunity (innate and adaptive), which play a vital role in the infectious and chronic disease (7). They are 
important immune system communication mediators and are important for host protection against pathogens (8). Leukocyte's ability to react to a microbial stimulus is affected by cytokines, which may cause systemic or localized immune response by transmitting signals through cellular receptors (9).

Bacillus Calmette-Guerin is an attenuated vaccine against Mycobacterium tuberculosis (M. tuberculosis) currently; it is the only authorized and widely used vaccine in the world for prevention of TB in human (10). It prepared from attenuated of $M$. bovis strain, it is the most effective vaccine to induce immunity against the three dangerous mycobacterial agents: (M. tuberculosis, $M$. lepraeand M. bovis) (11). This vaccine awarded a significant protection to experimentally infected lambs that measured through decreasing bacterial load and size of gross lesion (12).

Reviewing the available recent studies, there is no report concerning the preparation and evaluation of specific $M$. bovis- BCG TF, in addition to analysis of the cytokines IL17, MIF and IFN gamma in the recipient lambs. This study aimed to prepare specific $M$. bovis- BCG transfer factor and evaluate its clinical and some immunological activity in lambs.

\section{Materials and methods}

\section{Experimental animals}

A total number of 23 Awassi lambs, 3-4 months old, and 6 albino rabbits $(1.2-2 \mathrm{~kg})$ used in the current study, were housed in the animal farm of the College of Veterinary Medicine, University of Baghdad, they were fed, alfalfa and commercial assorted pellets, barley, bran and clean water. The animals were adapted for two weeks before starting the experiments to ensure disease-free and treated with albendazole and ivermectin, nasal swabs and fecal samples were collected for diagnosis of bacterial and parasitic infection (13). This study was approved by The Committee of Ethics Research of the Department of Internal and Preventive Medicine, College of Veterinary Medicine, University of Baghdad, Ministry of High Education and Scientific Research-Iraq (No. 1300/ 11-10-2020).

\section{Immunization and clinical examination}

Three Awassi lambs (3-4 months old) were used to prepare and extract the TF, two lambs, vaccinated twice S/C with $0.5 \mathrm{ml}$ of BCG (Pasteur and Danish, obtained from the Iraqi Ministry of Health) vaccine, two weeks' intervals as donor of specific TF (14), and the third lamb injected with normal saline used as a donor of non-specific TF. Lambs were monitored daily for clinical signs observations (temperature, respiratory rate and heart rate) 3 days post each immunization. After 4 weeks' success of immunization was confirmed by DTH-skin test.

\section{Delayed type hypersensitivity-skin test}

Four weeks post the immunization; the left flank area of the lamb was clipped and shaved carefully, and divided into two portions, the firstone was injected I.D with $0.1 \mathrm{~mL}$ of normal saline as a control, while the second one were injected with $0.1 \mathrm{~mL}$ of purified protein derivative (PPD). The thickness of skin reaction was assayed by the ruler at 72 hours after inoculation (15), TF was extracted from spleen cell of the lambs.

\section{Transfer factor extraction}

Two weeks post the 2 nd immunization, TF was obtained from the splenocyte of the vaccinated and control lambs as described previously (16), the spleen were removed aseptically, chopped and subjected to mechanical disintegration and grunt with clean sterile sand in sterile mortar and cell extract were suspended with sterile normal saline, the number cells was counted by hemacytometer, then it was adjusted at $5 \times 10^{8}$ cell $/ \mathrm{ml}$, and subjected to twelve times for freezing at $-20^{\circ} \mathrm{C}$ and thawing $\left(\right.$ at $37^{\circ} \mathrm{C}$ to disrupt the cells. The disrupted cells were centrifuged with a high speed cold centrifuge at $15000 \mathrm{rpm}$ for $40 \mathrm{~min}$. to eliminate cellular debris. Supernatant was filtrated by 0.45 and 0.22 Millipore filter, then ultra-filtered via Amicon filter (Merck Amicon-Ultra Centrifugal filter) to obtain the lysate containing transfer factor (4). The lysate was sterilized via a 0.22 Millipore filter, and kept at $-20^{\circ} \mathrm{C}$ for later use. The Sterility was confirmed by culturing of some drops of TF on blood agar and incubated at $37^{\circ} \mathrm{C}$ for 48 hours (16). Safety was confirmed by injection of TF in rabbits.

\section{First experiment}

To estimate the safety and biological activity of the prepared TF to transfer DTH-reaction, six rabbits were divided equally in to 2 groups, the first groups injected intra-peritoneal (I.P) with $2 \mathrm{~mL}$ equivalent to $5 * 10^{8}$ cells $/ \mathrm{mL}$ of specific $\mathrm{TF}$ and the second group injected I.P with $2 \mathrm{~mL}$ normal saline and monitored daily for any clinical signs and checked for cellular immunity by DTH test one week later (15).

\section{Second experiment}

Twenty Awassi lambs (3-4 months old) were divided equally and randomly into four groups to estimate the immunological activity of the prepared specific transfer factor, the first group was injected twice two weeks' interval S/C with $2 \mathrm{ml}$ (equivalent to $5 \times 10^{8} \mathrm{cells} / \mathrm{ml}$ ) of specific BCG-TF, similarly the $2^{\text {nd }}, 3^{\text {rd }}$ and $4^{\text {th }}$ groups were injected with non-specific TF $\left(2 \mathrm{ml}\right.$ equivalent to $5 \times 10^{8}$ cells $/ \mathrm{ml}$ ), BCG $0.5 \mathrm{ml}$ and normal saline $2 \mathrm{ml}$, respectively. Clinical examination was carried out to all animals at zero time and post injection, which includes heart rate, rectal temperature and respiratory rate, blood sample were

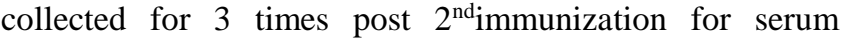


gathering. All the lambs were examined by DTH-skin test as described above at the $4^{\text {th }}$ week post immunization (15).

\section{Estimation of cytokines level}

Blood samples were obtained from jugular vein of all lambs at ${ }^{\text {st }}, 3^{\text {rd }}$ and $4^{\text {th }}$ weeks post $2^{\text {ndimmunization, sera }}$ were isolated by centrifugation at $2000 \mathrm{rpm}$ for $15 \mathrm{~min}$ (17). The cytokine concentrations of IL17, IFN- $\gamma$ and MIF were estimated according to the manufactures guidelines of the sheep ELISA Kit (MyBioSource USA).

\section{Statistical analysis}

Statistical analysis was carried out to detect the statistical variation between the groups by using two-way analysis of variance (ANOVA), the data were presented as mean and standard error.

\section{Results}

\section{Clinical examination post immunization}

Prior to immunization, all lambs in the four groups, specific $\mathrm{TF}, \mathrm{BCG}$, non-specific $\mathrm{TF}$ and control showed normal clinical parameters (body temperature respiratory and heart rates) Post immunization, only the BCG group revealed a significant increase at $\mathrm{P} \leq 0.05$ in these parameters, the peaks of at 24 hours then returned to normal ranges at 72 hours after immunization (Figures 1-3). Small local swelling was detected through palpation at the injection site of BCG vaccine, the peak of increased in body temperature, respiratory rate and heart rates were $40.2 \pm 0.10^{\circ} \mathrm{C}, 32.2 \pm 1.19 \mathrm{rate} / \mathrm{min}$, and $81.4 \pm 0.97 \mathrm{rate} / \mathrm{min}$ respectively.

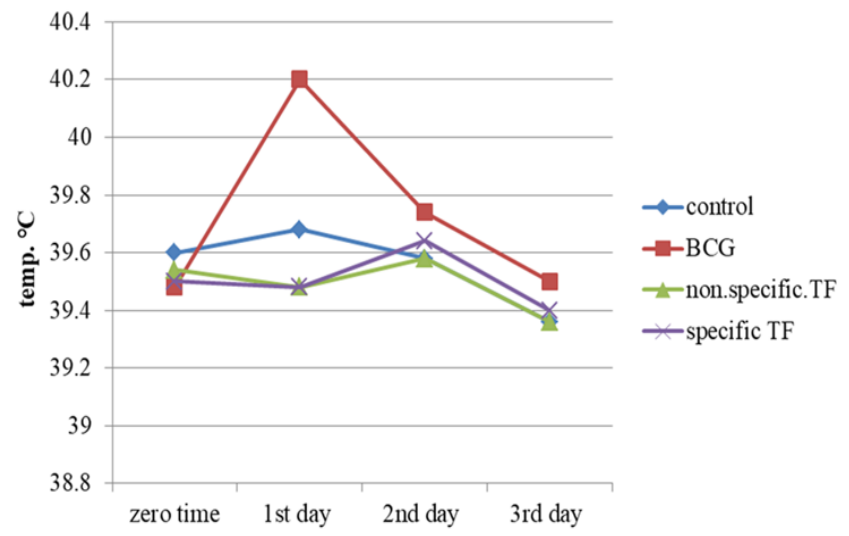

Figure 1: Body temperature in specific TF, BCG, nonspecific TF and control lambs.

\section{Delayed-type hypersensitivity test}

The results DTH test showed positive skin reaction in the specific TF recipient lambs and BCG vaccinated lambs only (Table 1), characterized by indurations, erythema and increase in skin thickness in the left flank of lambs after 24 hours. and became at peak after 48 hours and persisted to 72 hours, while the control and non-specific TF recipient groups showed no skin reaction at injection sites. The thickness of skin in specific TF recipient lambs and BCG vaccinated lambs were $>5 \mathrm{~mm}$.

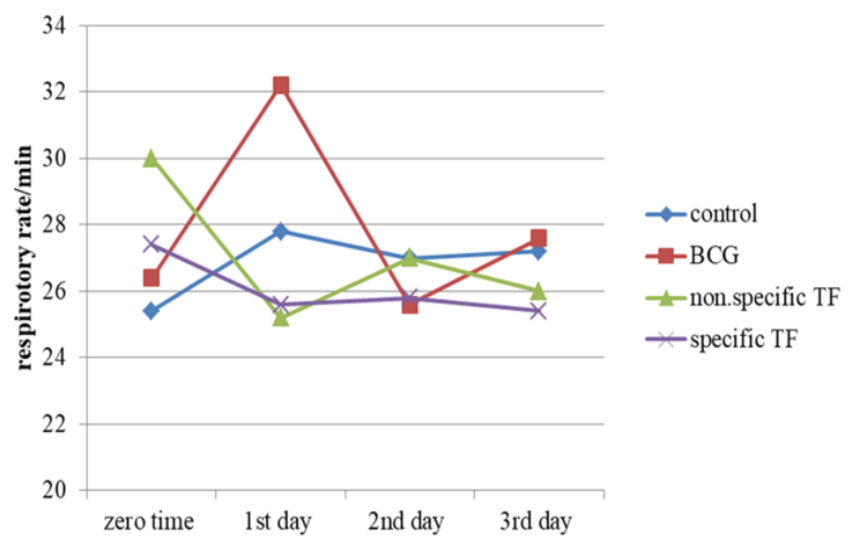

Figure 2: Respiratory rates/min. in specific TF, BCG, nonspecific TF and control lambs.

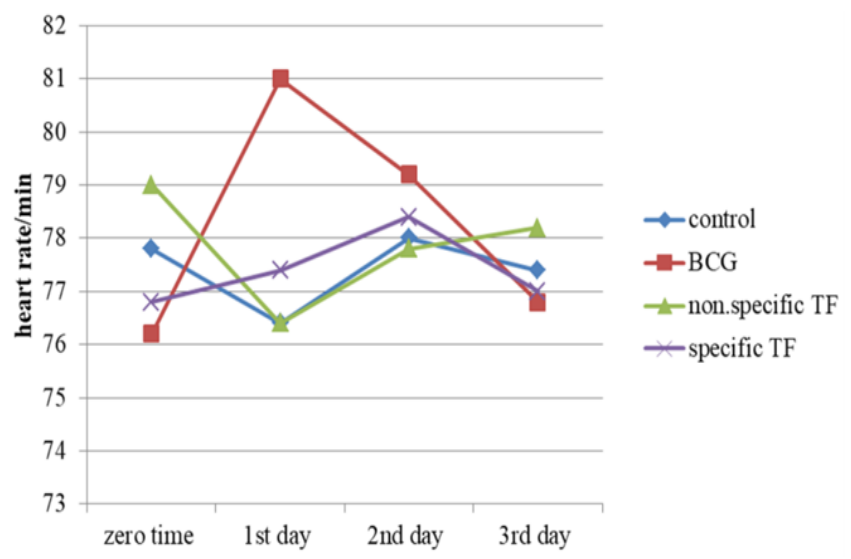

Figure 3: Heart rates/minute in specific TF, BCG, nonspecific TF and control lambs.

Table 1: skin reaction in specific $\mathrm{TF}, \mathrm{BCG}$, non-specific $\mathrm{TF}$ and control lambs

\begin{tabular}{lcc}
\hline Groups & No of lambs & Skin reaction \\
\hline Control & 5 & Negative \\
BCG & 5 & Positive \\
Nonspecific TF & 5 & Negative \\
Specific TF & 5 & Positive \\
\hline
\end{tabular}

\section{Interferon gamma}

The IFN- $\gamma$ cytokine level revealed a significant increase in the specific $\mathrm{TF}$ recipient and BCG groups in the comparison with non-specific $\mathrm{TF}$ and control lambs at $1^{\text {st }}$, $3^{\text {rd }}$ and $4^{\text {th }}$ week post booster immunization (Figure 4 ). 


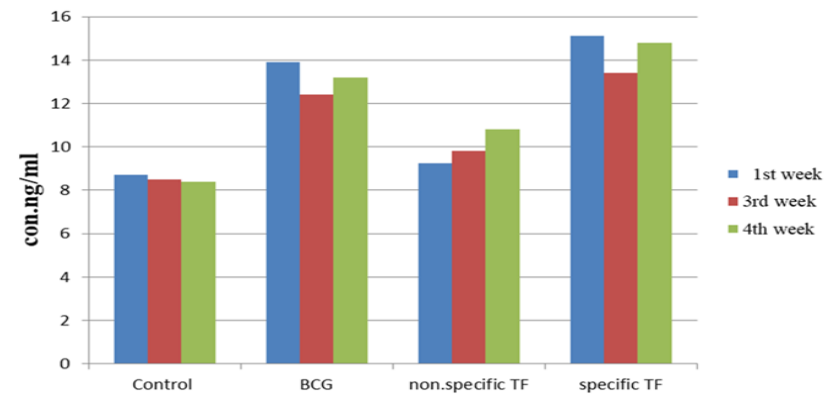

Figure 4: Serum IFN $\gamma$ level in specific TF, BCG, nonspecific TF and control lambs at $1^{\text {st }}, 3^{\text {rd }}$ and $4^{\text {th }}$ week post booster immunization.

\section{Interleukin-17}

The IL17 level revealed a significant increase at only in the specific TF recipient group in the comparison BCG, non-specific TF and control lambs at $1^{\text {st }}, 3^{\text {rd }}$ and $4^{\text {th }}$ week post booster immunization (Figure 5).

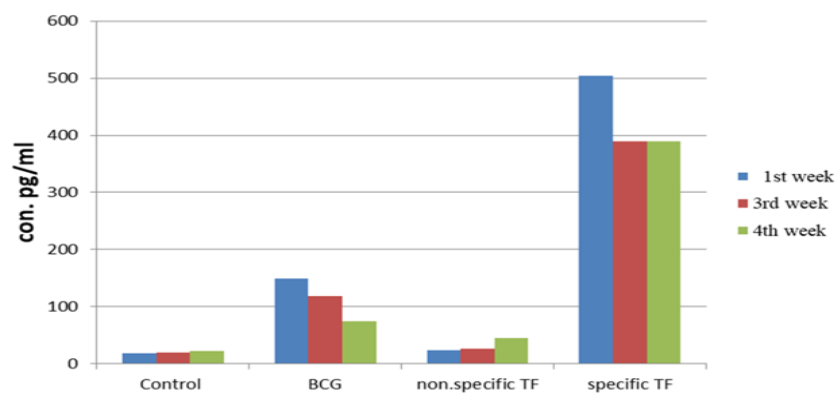

Figure 5: Serum level of IL17 in specific TF, BCG, nonspecific TF and control lambs at $1^{\text {st }}, 3^{\text {rd }}$ and $4^{\text {th }}$ week post booster immunization.

\section{Macrophage migration inhibitory factors}

The MIF level revealed a significant increase only in the specific TF recipient group in the comparison BCG, nonspecific TF and control lambs at $1^{\text {st }}, 3^{\text {rd }}$ and $4^{\text {th }}$ week post booster immunization (Figure 6).

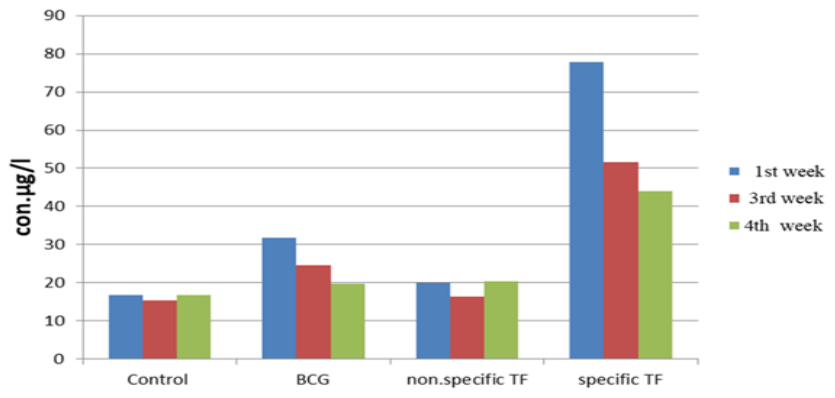

Figure 6: Serum level of MIF in specific TF, BCG, nonspecific TF and control lambs at $1^{\text {st }}, 3^{\text {rd }}$ and $4^{\text {th }}$ week post booster immunization.

\section{Discussion}

The results of immunization of lambs with BCG vaccine showed a significant increase in the clinical parameters (body temperature respiratory and heart rates) and small local swelling was detected through palpation at the injection site of BCG vaccine, this may be due to its immunological and inflammatory reactions as described formerly by Tizard (18). Similar finding was reported previously by Abdulrazaq and Al-Graibawi (19) they reported that rabbits injected with $M$. bovis-BCG revealed slight depression, swelling palpated at injection site by 96 hours and a slight increase in body temperature 38.2$40.1^{\circ} \mathrm{C}$. While the pilot study showed that the immunization of the rabbits with the prepared transfer factor was safe and did not induce systemic any adverse reactions, this may be due to the small size of the TF, which did not induce any inflammatory reaction (4).

Bacillus Calmette-Guerin is an attenuated vaccine prepared from attenuated strain of M. bovis, it is used to induce immunity against TB, and it is the most effective vaccine against all three major mycobacterial agents: $M$. tuberculosis, M. bovis and M. leprae (11). BCG is a safe vaccine have been already used in numerous kinds of animals TB hosts such as, cattle, goats, white tailed deer, badgers, possums, and African buffalo $(10,12)$.

The positive DTH-skin test reactivity in the specific TF recipient and BCG vaccinated lambs post I/D injection of PPD in comparison with no reaction in control and nonspecific TF recipient lambs in the present study, this may be due to cellular immune responses transferred by specific TF and that induced by BCG vaccine $(4,18,19)$. Cellular immunity plays a pivotal role in the defense of host against diseases; therefore, the assessment of CMI is important for evaluation of host defense against diseases. Various tests have been developed to estimate cell mediated immunity, among these tests, DTH- skin test, phagocytic index and cytokines assay (18). The traditional method for measuring the response of BCG vaccination by detecting the DTH-skin test reaction to intra-dermal PPD is tuberculin test (20).

The current study revealed significantly increased in the cytokines level (IFN- $\gamma$, IL17 and MIF) in specific TF recipient lambs compared to other lambs of experiment, this may be due to activation and differentiation of cells that responsible for these cytokines production (21). This results agreements with Whilleford et al. (22) who reported that post inoculation of mice with serum derived TF the IFN- $\gamma$ increased 77 fold ( 7.8 to $597 \mathrm{pg} / \mathrm{ml})$ at 24 hours. TF have the ability to regulate the immune responses, which can cause the synthesis of IFN- $\gamma$ from NK cells (5).

IL-17 and IFN- $\gamma$ and MIF are soluble, tiny molecular weight glycopeptides and polypeptides released by a various cell types that have enhancing or suppressive impacts on cellular proliferation, motility differentiation, 
and activation. Most of them are not constitutively produced, but are secreted in response to activation by infectious agents or them by products like: endotoxin, mechanical injuries, inflammatory mediators, and cytokines themselves $(7,8)$.

Transfer factor has the ability to regulate the innate immune responses, which induce the synthesis of IFN- $\gamma$ from NK cells (5). The innate and adaptive immune responses play a vital role in the prevention and control the mortality caused by COVID -19 infections $(23,24)$. For this reason, the $\mathrm{TF}$ is recommended as adjuvant therapeutic agent in the prevention and control symptoms associated with COVID-19, this recommendation depending on several studies concerning the using of TF in the SARSCoV-2 infection (25).

\section{Conclusions}

The current study demonstrated the efficacy of prepared specific $M$. bovis-BCG transfer factor to induce cell mediated immunity via DTH and increasing the serum concentration IL-17, IFN- $\gamma$ and MIF in recipient lambs.

\section{Acknowledgment}

Authors would like to thanks the College of Veterinary Medicine, University of Fallujah, Al-Anbar, College of Veterinary Medicine, University of Baghdad, Baghdad, and the College of Veterinary Medicine in supporting of current research and University of Mosul, Mosul for accepting this article, Iraq.

\section{Conflict of interest}

The authors declare that there are no conflicts of interest regarding the publication of this manuscript.

\section{Reference}

1. Lawrence HS. The cellular transfer factor of cutaneous hypersensitivity to tuberculin inman. Proc Soc Exp Biol Med. 1949;71:516-22. DOI: $10.3181 \% 2 F 00379727-71-17242$

2. Vetvicka V, Fernandez-Botran R. Non-specific immunostimulatory effects of transfer factor. Int Clin Pathol J. 2020;8(1):1-6. DOI: 10.15406/icpj1.2020.08.00197

3. Arnaudov A, Kostova Z. Dialysable leukocyte extracts in immunotherapy. Biotechnol Biotechnol Equip. 2015;29(6):1017-1023. DOI: $10.1080 / 13102818.2015 .1060136$

4. Al-Graibawi MA, Ati AT. The efficacy of prepared specific Pseudomonas aeruginosa transfer factor to protect mice against experimental challenge. Adv Anim Vet Sci. 2016;4(3):128-133. DOI: 10.14737/journal.aavs/2016/4.3.128.133

5. Krishnaveni M. A review on transfer factor an immune modulator. Drug Invent. 2013;5:153-156. DOI: 10.1016/j.dit.2013.04.002

6. Macias A E, and Guaní-Guerra E. Transfer Factor: Myths and Facts. Arch Med Res. 2020;10:12-16. DOI: 10.1016/j.arcmed.2020.06.016

7. Kawaguchi M, Adachi M, Oda N, Kokubu F, HuangS K.IL-17 cytokine family. J Allergy Clin Immunol. 2004;114(6):1265-1273. DOI: $10.1016 /$ j.jaci.2004.10.019
8. O'Shea J, Gadina M, Siegel R M. Cytokines and cytokine receptors. Clin Immunol. 2019;127-155. DOI: 10.1016/B978-0-7020-68966.00009-0

9. Grignani G, Maiolo A. Cytokinesand hemostasis. Haematol. 2000;85(9):967-972. DOI: $10.3324 / \% 25 x$

10. Saroha M, Faridi MMA, Batra P, Kaur I, Dewan DK. Immunogenicity and safety of early vs delayed BCG vaccination in moderately preterm (31-33 weeks) infants. Hum Vaccin Immunother. 2015;11:2864-2871. DOI: $10.1080 / 21645515.2015 .1074361$

11. Ameni G, Tafess K, Zewde A, Eguale T, Tilahun M, Hailu T, Sirak A, Salguero FJ, Berg S, Aseffa A, Hewinson RG, Vordermeier HM. Vaccination of calves with Mycobacterium bovis Bacillus CalmetteGuerin reduces the frequency and severity of lesions of bovine tuberculosis under a natural transmission setting in Ethiopia. Transbound Emerg Dis. 2018;65(1):96-104. DOI: 10.1111/tbed.12618

12. Balseiro A, Altuzarra R, Vidal E, Moll X, Espada Y, Sevilla I A, Pérez de Val B. Assessment of BCG and inactivated Mycobacterium bovis vaccines in an experimental tuberculosis infection model in sheep. PLoS One. 2017;12(7): 0180546. DOI: 10.1371/journal.pone.0180546

13. Jwher DM, Jarjees MT, Alshater AM. A study of the gastrointestinal parasites in awassi sheep and surrounding environment. Iraqi $\mathrm{J}$ Vet Sci. 2021;35(3):561-567 . DOI: 10.33899/ijvs.2020.127174.1478

14. Perez de Val B, Vidal E, Lopez-Soria S, Marco A, Cervera Z, Martı'n M. Assessment of safety and interferongammaresponses of Mycobacterium bovis BCG vaccine in goat kids and milking goats. Vaccine. 2016;34:881-886. DOI: 10.1016/j.vaccine.01.004

15. Al-Graibawi MA, Mohammad TA, Barak SS. Detection of bovine tuberculosis in three dairy cow stations in Iraq. Iraqi $\mathrm{J}$ Vet Sci. 2014;28(2):69-75. DOI: 10.33899/ijvs.2014.116888

16. Rozzo SJ, Kirkpatricksu C H. Purification of transfer factor. Mol Immunol. 1992;29:167-182. DOI: 10.1016/0161-5890(92)90098-I

17. Al-Thuwaini TM .The relationship of hematological parameters with adaptation and reproduction in sheep: A review study. Iraqi J Vet Sci. 2021;3593):575-580. DOI: 10.33899/ijvs.2020.127253.1490

18. TizardI R. Veterinary Immunology: An Introduction. $8^{\text {th }}$ ed. Philadelphia: WB Saunders Company; 2009. 3-9. [available at]

19. Abdulrazaq HE, Al-Graibawi MA. Effect of Mycobacterium bovistuberculosis BCG transfer factor vaccine on antibiotic resistant staphylococci in rats. Onl J Vet Res. 2021;25(2):124-130. http://onljvetres.com/transferratabs2021.htm

20. Ekram AA, KhalifaKA, NoriaRS. Evaluation of transfer factor protective efficacy against Tuberculosis in Guinea Pigs. Iraqi J Vet Med. 2005;29(2):112-121. [available at]

21. Alvarez Thull L, Kirkpatrick CH. Profiles of cytokine production in recipients of transfer factors. Biotherapy. 1996;9:55-59. DOI: 10.1007/BF02628657

22. Willeford BV, Shapiro-Dunlap T, Willeford KO. Serum derived transfer factor stimulates the innate immune system to improve survival traits in high risk pathogen scenarios. Drug Dev Res. 2017;78(5):189-195. DOI: $\underline{10.1002 / \text { ddr.21392 }}$

23. Al-AAlim AM, Hamad MA, Al-Ledani AA. Some insights of novel COVID 19 virus: structure, pathogenicity and immunity aspects. Iraqi J Vet sci. 2020;34(2):287-293. DOI: 10.33899/ijvs.2020.126898.1408

24. Al-Jameel W, Al-Mahmood SS. Similarities and differences of COVID-19 and avian infectious bronchitis from molecular pathologist and poultry specialist view point. Iraqi J Vet Sci. 2020;34(2):223-231. DOI: $10.33899 /$ ijvs.2020.126984.1426

25. Ferreira AO, Polonini HC, Dijkers E C. Postulated adjuvant therapeutic strategies for COVID-19. J Pers Med. 2020;10(3):80. DOI: $10.3390 / \mathrm{jpm} 10030080$ 
اختبار حساسية الجلا. استخلص العامل الناقل من الخلايا الطحالية

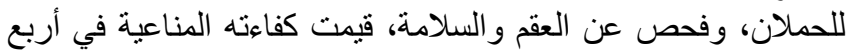

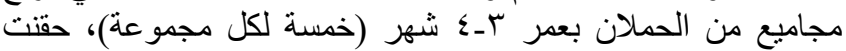

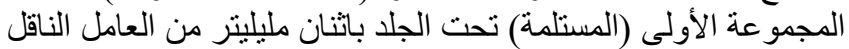

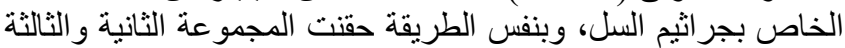

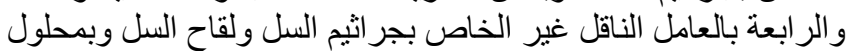

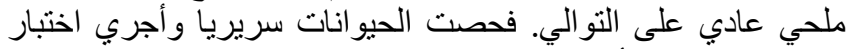

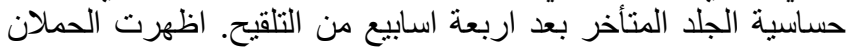

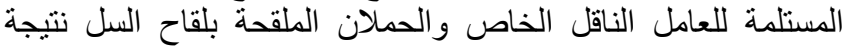

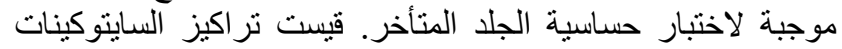

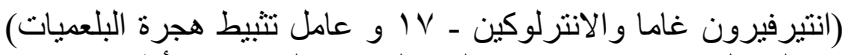

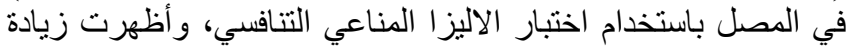

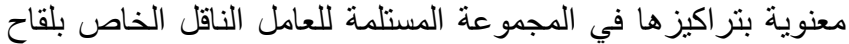

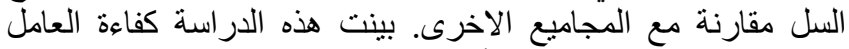

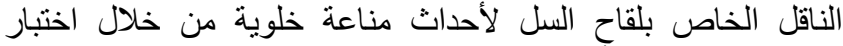
حساسية الجلد المتأخر وزيادة نراكيز السايتوكينات في الحملان

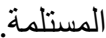

دراسة سريرية، مناعية للعامل الناقل الخاص بلقاح السل المحضر في الحملان

إيلاف عبدالقادر نايف' و مولود عباس علي الغريباوي'

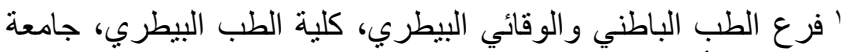

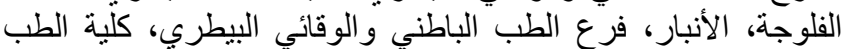
البيطري، جامعة بغداد، بغداد، العر اق القي

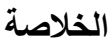

صمدت هذه الدراسة لتحضير وتقييم العامل الناقل الخاص بلقاح

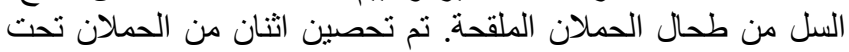

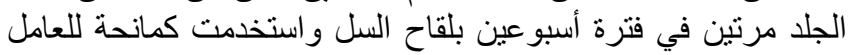

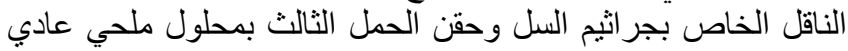

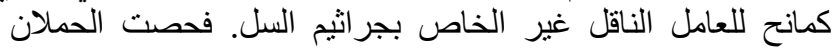

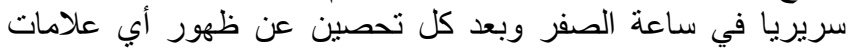
سريرية لمدة ثلاثة أيام. بعد أربعة أسابيع فحصت الحين عملان بوساطة 